Review

\title{
Pressure injury prevention for COVID-19 patients in a prone position
}

\section{Barakat-Johnson M, Carey R, Coleman K, Counter K, Hocking K, Leong T, Levido A and Coyer F}

Keywords acute respiratory distress, complications, positioning, pressure, prevention, prone

For referencing Barakat-Johnson $\mathrm{M}$ et al. Pressure injury prevention for COVID-19 patients in a prone position. Wound Practice and Research 2020; 28(2):50-57.

DOI https://doi.org/10.33235/wpr.28.2.50-57

Michelle Barakat-Johnson RN, MNursing, PhD

Skin Integrity Lead, Sydney Local Health District, NSW

Senior Lecturer, Faculty of Medicine and Health, University of Sydney, Camperdown, NSW

Adjunct Associate Professor, School of Nursing,

Queensland University of Technology, QLD

Ruaidhri Carey RN, Grad. Cert Critical Care

Clinical Nurse Educator, intensive care services

Royal Prince Alfred Hospital, Sydney Local Health District, NSW

Kerrie Coleman RN, BNSc, MN Clinical (Wound), MN (Chronic Disease NP)

Nurse Practitioner Complex Wound Management, Royal Brisbane and Women's Hospital, QLD

Kimberley Counter RN, MN

Clinical Nurse Educator, Intensive Care Services, Royal Prince Alfred Hospital, NSW

Kathy Hocking RN, Grad Dip (Wound Care)

Acting Clinical Nurse Consultant Skin Integrity Service, Royal Brisbane and Women's Hospital, QLD

Tom Leong RN, MNursing

Clinical Nurse Consultant, Skin Integrity and Wound Management, Royal Prince Alfred Hospital, Sydney Local Health District, NSW
Annabel Levido RN, BN, GradCert(Critical Care Nursing), MAppManagament (Nursing)

Clinical Nurse Nursing Research, Intensive Care Services, Royal Brisbane and Women's Hospital, QLD

Fiona Coyer* RN, MSc Nursing, PhD

Professor of Nursing, Conjoint appointment with the School of Nursing Queensland University of Technology and Royal Brisbane and Women's Hospital, QLD

Visiting Professor, Institute for Skin Integrity and Infection Prevention, University of Huddersfield, UK Email f.coyer@qut.edu.au

${ }^{*}$ Corresponding author

\section{Abstract}

Prone positioning is a method used to manage ventilatorassociated lung injury and promote oxygenation in severe acute respiratory distress syndrome (ARDS). With the COVID-19 pandemic and ever-increasing numbers of patients presenting with clinical pictures of ARDS, critical care practice guidelines and governing bodies are recommending prone positioning for adult patients with ARDS related to severe COVID-19 infection. Complications associated with prone positioning in critical care have the potential to cause patient morbidity. Common complications with prone positioning include the development of pressure injuries (PIs) on the forehead, chest, pelvis, chin, shoulders, genitalia, iliac crest and knees. Ocular damage and musculoskeletal issues may also occur. These complications are largely avoidable by implementing appropriate interventions. This article summarises current best practice and literature on 
interventions to reduce skin injury and other complications associated with prone positioning of COVID-19 patients with ARDS.

\section{Key points}

What is already known about this topic

- Eight randomised controlled trials have demonstrated positive effects of prone positioning for mechanically ventilated patients with acute respiratory distress.

- Patients remain in the prone position for extended periods thus creating anatomical areas at significant risk for pressure injury $(\mathrm{Pl})$ development.

- Prior to proning the patient, consideration should be given to the appropriate support surface, care of all medical devices, and possible application of prophylactic dressings on key anatomical pressure points.

\section{What this manuscript contributes}

- This article provides a summary of current best practice and literature on interventions to reduce Pls associated with prone positioning.

- Careful positioning and efficient use of adjunct therapies in line with a PI prevention program may help reduce the incidence of prone positioning complications.

\section{Introduction}

Positioning a critically ill patient in bed is a key fundamental activity that clinicians routinely incorporate into daily practice. The correct position can have a positive impact on the patient's health and recovery. However, maintaining certain positions over prolonged periods can pose risks, especially to the integumentary system, due to duration and intensity of pressure from underlying surfaces or devices, therefore resulting in tissue damage.

With the rapid evolution of the COVID-19 pandemic, an increasing number of patients are being admitted to intensive or critical care units (ICU/CCU) and cared for in a prone position during mechanical ventilation. The Australian healthcare system has had to respond rapidly to exponential growth in the numbers of individuals affected by COVID-19. COVID-19, also known as SARS-CoV-2, is an infectious respiratory illness caused by a new strain of novel coronavirus. The coronaviruses are a large family of viruses that cause illnesses ranging from the common cold to more severe life-threatening complications such as acute respiratory distress syndrome (ARDS) ${ }^{1}$. The best research evidence recommends that treatment of ARDS is carried out with the patient is in a prone position ${ }^{2}$.

This article will discuss current practices to minimise skin injury and other complications when the patient is in the prone position. This article can be used as an additional resource for clinicians caring for patients in a prone position.

\section{Severe COVID-19 respiratory failure}

Severe COVID-19 exhibits as a primary respiratory failure with an ARDS-like clinical picture.

ARDS is characterised by inflammation of the lungs, hypoxia and pulmonary oedema requiring mechanical ventilation ${ }^{3}$. People with ARDS experience severe shortness of breath, increased work of breathing, fever, dyspnoea, hypotension and fatigue. ARDS incidence rates vary widely in the literature. This is due to differences in the clinical settings, patient populations and methodologies employed to determine the rates $^{4}$. A 2014 study examining the incidence and outcome of ARDS in 459 ICUs in 50 countries reported an incidence of $10.4 \%$ of all ICU admissions (5.5 cases per ICU bed per year $)^{5}$. A recent study conducted by Diamond (2020) in the United States suggested an estimated incidence of ARDS ranged from 64.2-78.9 per 1000 persons per year ${ }^{6}$. The morbidity and mortality outcomes of patients with ARDS are significant; most patients with ARDS develop pneumonia or sepsis. It is estimated that $8.8 \%$ of all patients with ARDS receiving mechanical ventilation develop acute lung injury? For patients with COVID-19, ARDS has been shown to be a strong predictor of death ${ }^{4}$.

The major focus of management for severe COVID-19 respiratory failure is avoidance of ventilator-induced lung injury while optimising gas exchange via lung protective ventilation strategies. Proning assists with this. Prone positioning has been used for many years to improve oxygenation in patients who require mechanical ventilation ${ }^{8,9}$. Proning has a number of physiological benefits. These include increased oxygenation, improved respiratory mechanics through the reduction of over-inflated lung areas and increased alveolar recruitment, and reduced ventilator-induced injury, also known as barotrauma and volutrauma, through homogenised distribution of stress and strain dynamics in the lung. Volutrauma also occurs during mechanical ventilation with high levels of positive end expiratory pressure often used in ARDS. A number of studies have demonstrated that early prone positioning during mechanical ventilation improves oxygenation and reduces the mortality rate in individuals with ARDS ${ }^{10-12}$. Further, current clinical practice guidelines ${ }^{2}$ strongly recommend prone positioning for patients with ARDS.

\section{Prone positioning}

In the prone position, the patient is face down with their head in a neutral position. This position is most commonly used for spine and neck surgeries, neurosurgery, colorectal surgeries and vascular surgeries and, more recently, to treat COVID-19 patients.

Patients treated in a prone position during mechanical ventilation are usually in a prone position for prolonged periods $>12$ hours per day. A large multi-centre randomised controlled trial, conducted in Europe from 2008 to 2011, demonstrated beneficial effects of prone positioning for 
16 hours (16\% 28-day mortality) compared to supine positioning (32.8\% 28-day mortality) in patients with severe ARDS $^{12}$. Prone positioning during mechanical ventilation is consequently strongly recommended in adults with ARDS, but entails an increased risk of complications; specifically, $\mathrm{Pls}^{13,14}$. Data from the same multi-centre randomised control trial reported that Pls were significantly higher in patients with ARDS who were treated in a prone position compared to those who were treated in a supine position ${ }^{13}$. High-risk body areas for Pls are noted to include the face, ears, chest, pelvis, chin, shoulders, nipples, genitalia, iliac crest and knees $^{13-16}$. Thus, ensuring the patient is correctly positioned and protected from injury is a crucial activity.

\section{Pressure injury prevention}

Pressure injuries are caused by unrelieved pressure, or friction and shear in combination with pressure, on soft tissues and bony prominences for prolonged periods ${ }^{17}$. Pressure injuries are recognised as one of the most costly and complicated conditions, and have been listed as one of the 15 preventable hospital-acquired complications in Australia ${ }^{18}$. While hospitalised patients with reduced mobility have an increased risk of developing Pls, critical care patients are at even greater risk because of their illness severity ${ }^{19}$, immobility, mechanical ventilation ${ }^{20}$, infrequent repositioning ${ }^{21}$, and the use of a high number of medical therapeutic devices applying sustained pressure ${ }^{22}$. Common areas for Pls to develop in critically ill patients from medical devices include the sacrum, the heels (from lying supine or on the side), and on the mouth, ears and nose ${ }^{19-22}$. Conversely, when patients are nursed in a prone position, Pls can occur in different locations such as on the forehead, chest, pelvis, chin, shoulders, genitalia, iliac crest and knees, dorsal feet, and toes (Figure 1) ${ }^{17}$.

Prevention of Pls involves routine skin assessment, frequent off-loading of pressure and repositioning, and use of appropriate pressure redistribution surfaces ${ }^{17,23,24}$. Frequent off-loading and repositioning reduces pressure, shear and friction ${ }^{24}$. However, this can pose a challenge for patients in a prone position receiving mechanical ventilation. Specifically, these patients remain in the prone position for at least 12 hours with the head repositioned every 2-4 hours. Only small micro shifts in position are performed during the proned period because of the risk of dislodgement of tubes and devices and concern over the loss of physiological benefit of proning ${ }^{25,26}$. Additionally, moving patients into and out of a prone position is labour-intensive, requiring numerous highly trained staff members. Therefore, alternative approaches to reducing pressure, shear and friction should be considered. Pressure redistributing surfaces, head positioners and prophylactic dressings are some alternate approaches shown to alleviate pressure, shear and friction ${ }^{17}$.

\section{Pressure redistributing surfaces}

Any patient who is immobile and considered at high risk of developing a PI benefits from having an appropriate support surface ${ }^{17}$. Support surfaces function to redistribute pressure and shear at the skin surface, promoting immersion, envelopment and alleviating tissue deformations ${ }^{27,28}$. A number of local guidelines recommend the use of constant low air loss support surfaces for critically ill patients ${ }^{29,30}$. However, the current International guideline does not recommend one over the other ${ }^{17}$. In general, multiple studies support the theory that support surfaces, coupled with repositioning patients, prevent tissue damage and reduce the risk of $\mathrm{Pl}^{28}$. Commonly used mattresses in Australian ICUs comprise reactive air (known as low air loss) or active (known as alternating/dynamic) mattresses, with active being the most commonly used in $\mathrm{ICU}^{31}$.

Reactive air mattresses provide constant low air pressure to reduce the contact point pressure between the skin and the surface. These mattresses work on immersion and envelopment by evenly distributing weight over a surface

Figure 1. Areas of potential pressure injury formation when lying in a prone position

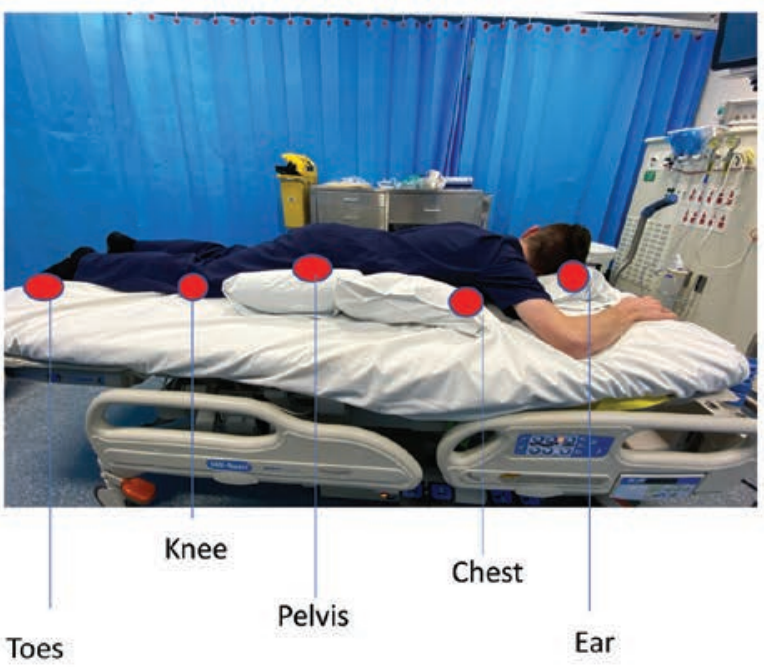

Wound Practice and Research

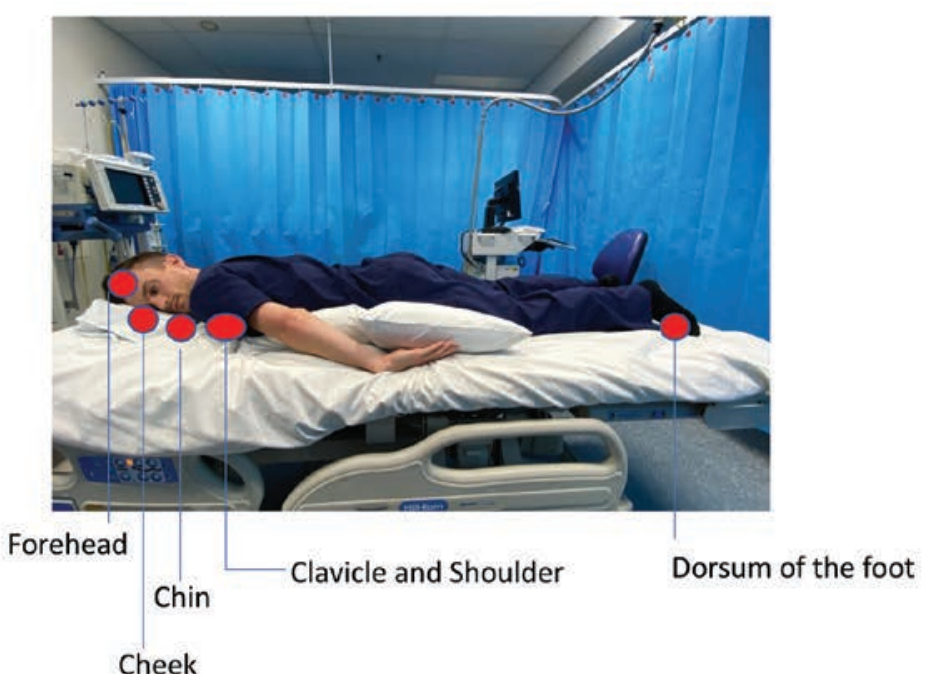




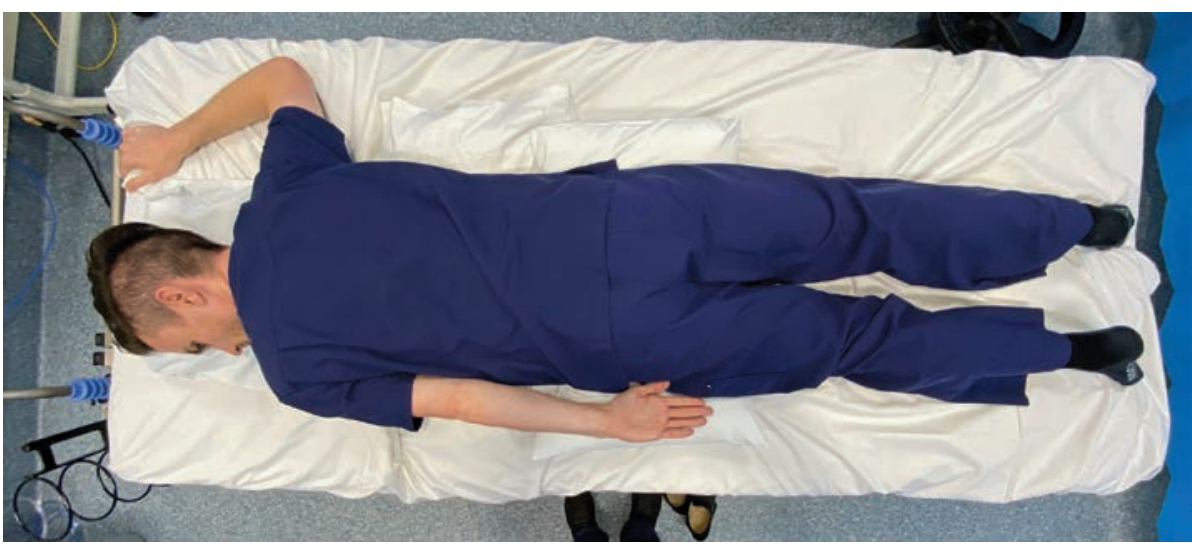

Figure 2. Using pillows to off-load pressure when lying in a prone position

skeleton. When a patient is positioned with poor skeletal alignment, muscle strain and contractures can occur. The National Pressure Injury Advisory Panel (NPIAP) ${ }^{34}$ recommend prone positioning with pillows to off-load pressure and reposition in a swimming position (Figure 2) with the raised arm at less than a $90^{\circ}$ angle from the shoulder to prevent brachial plexus injury. Both arms are moved every 2 hours into the swimming position in synchrony with head repositioning; by alternating the arms this ensures the side where the endotracheal tube is placed can be

area $^{32}$. They also have an advanced microclimate technology which eliminates excessive heat and moisture. An active mattress is made up of a series of air cells that regularly inflate or deflate to periodically relieve any pressure applied to the tissue from lying. The inflation and deflation of air cells in an active mattress alters both the magnitude and duration of loading. Altering the magnitude and duration of pressure leads to greater pressure relief, reduction in moisture, and less shear and friction at the skin surface ${ }^{24}$.

A number of systematic reviews have reviewed the literature on support surfaces, especially active and reactive, and have concluded that, compared to basic standard mattresses, active mattresses, along with repositioning, reduces risk of $\mathrm{PIs}^{28,33}$. The choice of mattress should take into account the patient's special needs and their risk of developing Pls, and is an important consideration when patients are in a prone position.

\section{Body position}

Skeletal alignment and correct positioning are other important considerations when positioning patients in a prone position (Figure 3). The goal of good skeletal alignment is to position the patient so that their body is aligned in such a way that there is minimal undue stress placed on the muscles and

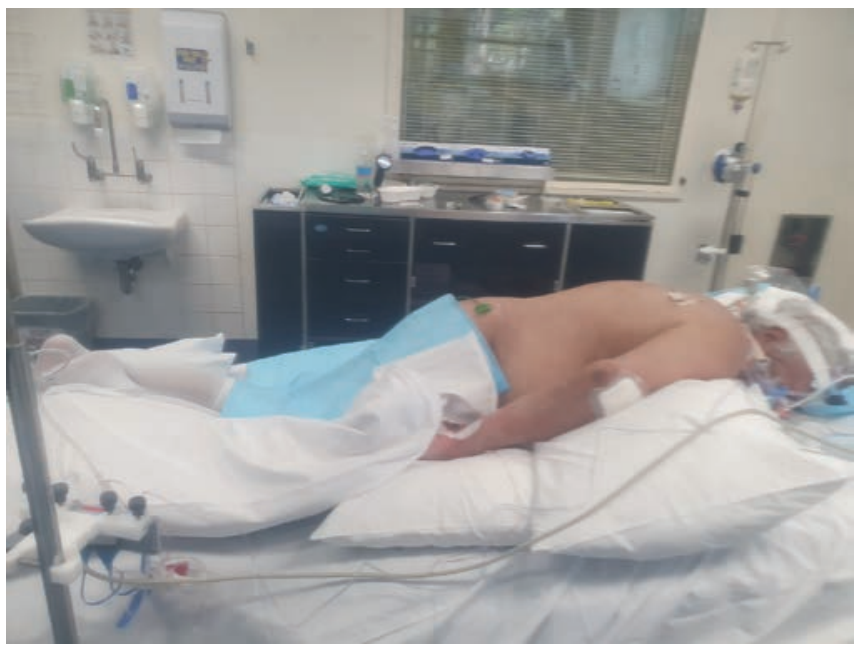

Figure 3. COVID-19 proned patient in the intensive care unit visualised and is not obstructed by the arm. Alternating the arms and the head every 2 hours is also recommended in order to avoid the development of Pls on the elbows and the face ${ }^{12}$.

\section{Care of medical devices}

Given the multitude of medical and therapeutic devices used to care for the critically ill patient, attention to medical devices is always paramount ${ }^{22}$. This is particularly evident when the patient is in the prone position where access to devices may be more difficult in this position. Nevertheless, the current International guideline recommendations for the prevention of medical device-related Pls still apply. Namely, that the tension of the devices and their securement is regularly monitored, that the skin under and around the device is regularly assessed for signs of $\mathrm{PI}$ development, that, where possible, the device should be rotated in the orifice to reduce or redistribute pressure, and that consideration is given to the application of a prophylactic dressing under the device to alleviate pressure ${ }^{17}$.

\section{Optical injuries}

Kwee and Rozen ${ }^{35}$ conducted a systematic literature review of the complications related to prone positioning during surgery. They identified a number of complications with high quality evidence on postoperative vision loss, particularly ischaemic optic neuropathy and orbital compartment syndrome. Despite its low rate of incidence $(0.5-1 \%$ per annum), the ramifications for the patient upon survival has a large negative impact and measures need to be implemented to prevent it. Ischaemic optic neuropathy and orbital compartment syndrome are caused when the orbital pressure is high enough to raise the intraocular pressure leading to a decrease in perfusion of the optic nerve resulting in ischaemia and blindness. Intra ocular pressure can also be increased due to obstruction in the outflow of aqueous humour whilst in the prone position. Other optical injuries include corneal abrasions and impaired function of the extraocular muscles caused by impingement.

Prevention for such an injury involves the use of headrests to avoid direct pressure to the orbits ${ }^{36,37}$. Frequent monitoring of 
eye positions every 20 minutes with a mirror attachment to the headrest has also been recommended ${ }^{37}$. Implementation of positioning the bed into reverse Trendelenburg can also reduce optical pressure and oedema ${ }^{37}$.

\section{Head positioners}

The different type of head positioners available for PI reduction include high specification foam such as the Dupaco ProneView ${ }^{\circledR}$ positioner, fluidised silicone such as Mölnlycke Z-Flo ${ }^{\mathrm{TM}}$, and air-filled positioners such as the Roho ${ }^{\circledR}$ neoprene positioner. However, studies on these devices to assist in the prevention of Pls with patients in a prone position are scarce. Some devices, particularly ring or donut-shaped devices, have been found to cause more shear and pressure at the skin surface and internally, and in fact increase the risk for the development of $\mathrm{PIs}^{38,39}$. Katzengold and Gefen ${ }^{38}$ used finite element modelling to compare a foam pad with a silicone head positioner (Z-Flo ${ }^{\mathrm{TM}}$, Mölnlycke). They demonstrated that the Z-Flo ${ }^{\mathrm{TM}}$ alleviated shear, reduced tissue distortion and minimised focal contact pressures at the occiput region. A recent prospective study ${ }^{40}$ utilising the $\mathrm{Z}-\mathrm{FlO}^{\mathrm{TM}}$ conducted in a large critical care service in Australia found the Z-Flo ${ }^{\mathrm{TM}}$ significantly reduced occipital Pls by $87.7 \%$ (16/63; $25.4 \%$ historical control vs $2 / 64 ; 3.13 \%$ interventional group; $\left.x^{2}(1)=12.95, p<0.001\right)$. Further, ICU nurses provided positive evaluations of the device, identifying the benefits of the device for patients in the intensive care setting ${ }^{40}$. For example, nurses commented how easy the device was to mould to the patient's facial contours and position and that creating divots in the positioner helped to keep tubes and devices out of the way.

Like the occipital region, the temple region is an area that is susceptible to PI as it does not have thick subcutaneous tissue layers to assist in distributing external pressure and shear. In the prone position the temple region is exposed to pressure. The Z-Flo ${ }^{\mathrm{TM}}$ device can be moulded into shape, placed in a pillow cover and positioned under the patient's forehead to redistribute pressure and reduce tissue deformation of the temple region. Divots can be formed in the positioner to keep it away from tubing. Some considerations when using positioners under the forehead of patients in a prone position include ensuring micro shifts are carried out every 2 hours, ensuring the fluidised positioner is remoulded every 2 hours, conducting regular skin assessment, changing the pillowcase if it is moist due to perspiration, and ensuring the endotracheal tube is positioned correctly. Anecdotal reports since COVID-19 have found this positioner to be practical and easy to apply.

Other head positioners have been used in patients who are placed in a prone position for surgery but, like occipital positioners, literature on these devices is limited. In a prospective pilot study, McMichael and Place $(2008)^{41}$ reported the Roho ${ }^{\circledR}$ neoprene positioner resulted in significantly fewer forehead and chin Pls than other conventional forehead positioners. Similar results were found in a randomised control trial testing three facial positioners in 66 elective surgery patients where patients who had the Dupaco ProneView ${ }^{\circledR}$ positioner had less facial $\mathrm{Pls}^{36}$. Regardless of the positioner used, small frequent movements (microshifts) ${ }^{34}$ should be carried out to relieve pressure, shear and friction. Further, adjunct interventions, such as prophylactic dressings, can be used in conjunction with head positioners.

\section{Prophylactic dressings}

Prophylactic dressings have become a widely accepted adjunct method of preventing the development of PIs in patients considered to be at risk $^{17,42-46}$. The types of prophylactic dressings available include soft silicone foam multi-layered dressings to redistribute pressure and shear such as Mepilex ${ }^{\circledR}$ Border and Allevyn Life $^{\mathrm{TM}}$, polyurethane dressings such as OPSITE FLEXIFIX ${ }^{\mathrm{TM}}$, and hydrocolloid dressings such as DuoDERM ${ }^{\circledR}$ Extra Thin to alleviate friction.

However, much of the research has been predominantly in patients in a supine position, with evidence limited to studies that did not investigate the use of these dressings in the prone position. The use of these dressings to prevent Pls in patients in prone position is largely anecdotal, with prospective trials and management protocols still evolving. Two studies suggest that soft silicone foam multi-layered prophylactic dressing demonstrated adjunctive efficacy in the prevention of Pls on areas such as the chest and lilac crests ${ }^{47,48}$. In the recent trial conducted in operating rooms recruiting patients who underwent spinal surgery in the prone position (the BOSS trial), soft silicone foam multi-layered prophylactic dressings were compared to polyurethane dressings ${ }^{48}$. This study found significantly less PI developed in the Pls in the soft silicone foam multi-layered dressing $(p=0.019$, OR 0.23 , $95 \% \mathrm{Cl}$ 0.05-0.79) ${ }^{48}$. Public health emergencies, such as the COVID-19 pandemic, create an urgent need to prevent negative patient outcomes, such as Pls, and, in doing so, to use interventions that are currently available albeit not directly tested in patients in the prone position. Therefore, the use of prophylactic dressings in prone positioning is an important consideration.

Prophylactic dressings are usually applied over bony prominences and, where appropriate, under medical devices. Selection of the type of prophylactic dressing should take into consideration a number of factors. These include whether the dressings have been proven to reduce PI occurrence in rigorous studies; the anatomical location and the shape of the dressing; the layers of the dressing; that, if placed under a medical device, the dressing must not interfere with the device; and whether the dressing has evidence of moisture management.

Not all dressings when used prophylactically have the same properties and it is important to use dressings that are supported by robust evidence ${ }^{46}$. The most studied dressing with the strongest evidence in the prevention of Pls in critically ill patients is the multi-layer soft silicone 
bordered dressing. This dressing has undergone laboratory computational modelling which has shown these dressings to reduce friction, shear and pressure ${ }^{45}$, with the most recent modelling of Mepilex ${ }^{\circledR}$ Border Flex demonstrating reduction in high risk stresses by up to $70-80 \%$ in soft tissues over the iliac crest when exposed to multi-directional forces due to the flex component of the dressing that allows movement in all directions ${ }^{49}$. Moisture reduction and microclimate management have also been observed ${ }^{50}$.

The Border Trial I and Border Trial II43,34 randomised controlled trial studies demonstrated that multi-layer soft silicone foam dressings were effective in the prevention of Pls on the sacrum and heels of critically ill patients. Similar findings were observed in a recent observational study conducted in 38 acute and critical care facilities in the United States ${ }^{51}$. The investigator reported a significant decrease of $\mathrm{PI}$ rates over a 5-year period following the introduction of soft silicone foam multi-layered prophylactic dressings as part of a $\mathrm{PI}$ prevention program.

Trial designs have evolved over time. Santamaria et al.'s recent Border Trial III tested the effectiveness of soft silicone foam multi-layered prophylactic dressings on residential aged care individuals who were mostly incontinent of urine and/or faeces ${ }^{42}$. The dressings performed well in incontinent patients when staff positioned the dressing accurately and ensured the skin was clean and dry before application. This demonstrates that the dressing has ability to wick moisture that is integral to allow perspiration to evaporate and not remain on the skin; although not measured in this study, this is an important consideration in proned patients.

Other types of silicone foam dressings have not yet undergone a number of rigorous studies to show their effectiveness in the prevention of PIs, particularly in critically ill patients. A recent pragmatic trial of 393 elderly patients with hip fractures demonstrated that a silicone foam dressing resulted in a reduction of sacral Pls $(8 \text { vs } 28 ; 95 \% \mathrm{Cl} 0.14-0.61)^{52}$. In addition, some quality improvement programs have implemented silicone foam dressings to reduce the onset of Pls. For example, Sammon identified that the use of a silicone foam dressing as part of a PI program helped reduce the onset of sacral PIs by $40 \%$ (from $2.3 \%$ to $1.5 \%)^{53}$.

It is accepted that prophylactic dressings should be used in conjunction with other preventative strategies such as small, frequent repositioning shifts, pressure redistributing mattresses, and regular skin assessment. Pulling back the dressings and inspecting the skin beneath on a daily basis is recommended. The frequency of dressing changes for prevention of Pls is according to manufacturer instructions. Figure 4 provides a visual representation of the application of a prophylactic dressing, in this case Mepilex ${ }^{\circledast}$ Border Flex, in relation to the dressing type, size and location. For ease of use in clinical practice, dedicated packs of dressings can be made up for each prone positioning event. Packs would include quick instructions in dot points on how and
Figure 4. A visual representation of the application of a prophylactic dressing

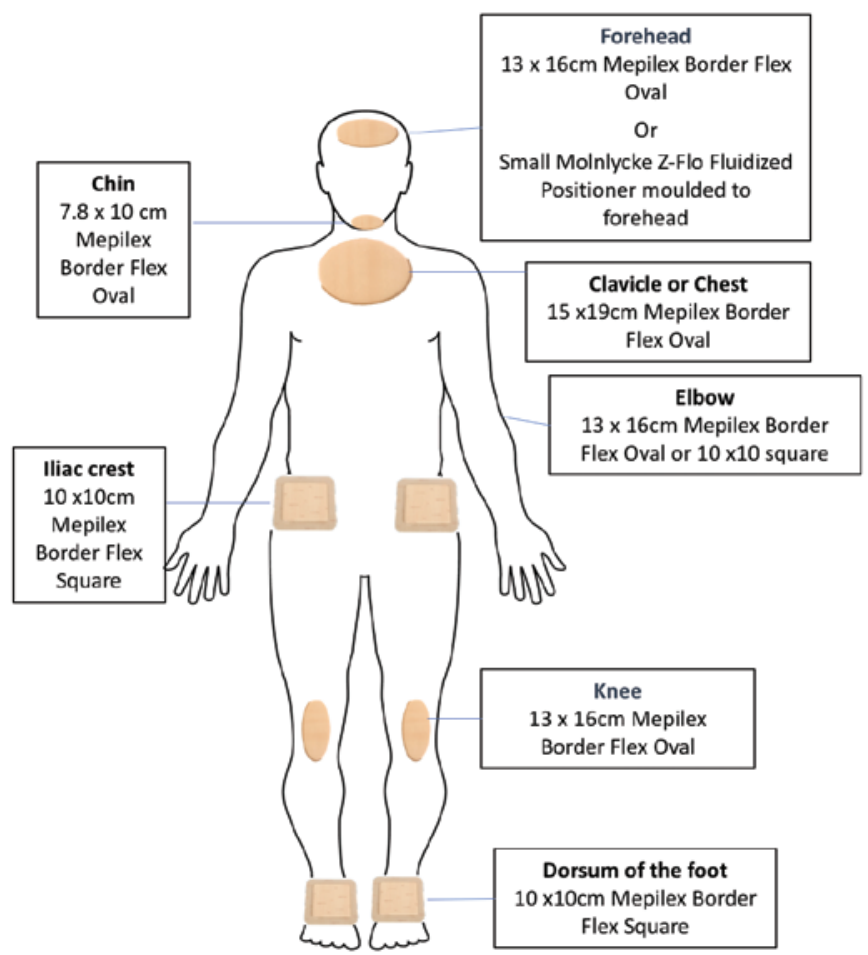

where to apply preventative dressings and a picture showing anatomical placement of the dressings.

More research is required to establish the efficacy of prophylactic dressings in the prevention of $\mathrm{Pl}$ and, importantly, further studies are critically needed in this area to determine the effectiveness of prophylactic dressings, dressing types, and their application in preventing PI when patients are in a prone position.

\section{Conclusion}

Prone positioning is a recommended management strategy for critically ill COVID-19 patients with manifestations of ARDS. While beneficial for the treatment of ARDS, prone positioning can cause injuries to the integumentary system and other complications. Careful positioning, diligent skin assessment, and efficient use of adjunct therapies in line with a $\mathrm{PI}$ prevention program may help reduce the incidence of prone positioning complications.

\section{Ethics}

Written informed consent was obtained for the use of clinical images in the manuscript.

\section{Conflict of interest}

The authors declare no conflicts of interest.

\section{Funding}

The authors received no funding for this study. 


\section{References}

1. Australian Government Department of Health. Health alerts. Available from: https://www.health.gov.au/news/health-alerts/ novel-coronavirus-2019-ncov-health-alert/what-you-need-toknow-about-coronavirus-covid-19.

2. Fan E, Del Sorbo L, Goligher EC, et al. An official American Thoracic Society/European Society of Intensive Care Medicine/ Society of Critical Care Medicine clinical practice guideline: mechanical ventilation in adult patients with acute respiratory distress syndrome. Am J Respir Crit Care Med 2017;195(9):125363.

3. Bernard GR, Artigas A, Brigham KL, et al. The AmericanEuropean Consensus Conference on ARDS. Definitions, mechanisms, relevant outcomes, and clinical trial coordination. Am J Respir Crit Care Med 1994;149(3 Pt 1):818-24.

4. Wang L, He W, Yu X, et al. Coronavirus disease 2019 in elderly patients: characteristics and prognostic factors based on 4-week follow-up. [published online ahead of print, 2020 Mar 30]. J Infect 2020;S0163-4453(20)30146-8. doi:10.1016/j.jinf.2020.03.019

5. Bellani G, Laffey JG, Pham T, et al. Epidemiology, patterns of care, and mortality for patients with acute respiratory distress syndrome in intensive care units in 50 countries. JAMA 2016;315(8):788-800.

6. Diamond M, Peniston HL, Sanghavi D, Mahapatra S. Acute Respiratory Distress Syndrome. Available from: https://www. ncbi.nlm.nih.gov/books/NBK436002/. 2020.

7. Fuller BM, Mohr NM, Dettmer M, et al. Mechanical ventilation and acute lung injury in emergency department patients with severe sepsis and septic shock: an observational study. Acad Emerg Med 2013;20(7):659-69.

8. Lamm WJ, Graham MM, Albert RK. Mechanism by which the prone position improves oxygenation in acute lung injury. Am $\mathrm{J}$ Respir Crit Care Med 1994;150(1):184-93.

9. Henderson AC, Sa RC, Theilmann RJ, Buxton RB, Prisk GK, Hopkins SR. The gravitational distribution of ventilationperfusion ratio is more uniform in prone than supine posture in the normal human lung. J Appl Physiol 2013;115(3):313-24.

10. Taccone $P$, Pesenti $A$, Latini $R$, et al. Prone positioning in patients with moderate and severe acute respiratory distress syndrome: a randomized controlled trial. JAMA 2009;302(18):1977-84.

11. Sud S, Friedrich JO, Adhikari NKJ, et al. Effect of prone positioning during mechanical ventilation on mortality among patients with acute respiratory distress syndrome: a systematic review and meta-analysis. CMAJ 2014;186(10):E381-E90.

12. Guérin $\mathrm{C}$, Reignier $\mathrm{J}$, Richard $\mathrm{J}-\mathrm{C}$, et al. Prone positioning in severe acute respiratory distress syndrome. $\mathrm{N}$ Engl $\mathrm{J}$ Med 2013;368(23):2159-68.

13. Girard R, Baboi L, Ayzac L, Richard JC, Guerin C. The impact of patient positioning on pressure ulcers in patients with severe ARDS: results from a multicentre randomised controlled trial on prone positioning. Intensive Care Med 2014;40(3):397-403.

14. Joshi D, Duvuuri P, Mireles-Cabodevila E, Sasidhar M, Duggal A. Prone position ventilation and the development of pressure ulcers: experience from a tertiary care referral center. Am J Respir Crit Care Med 2015;191:A3138.

15. Bunker DLJ, Thomson M. Chin necrosis as a consequence of prone positioning in the intensive care unit. Case Rep Med 2015;2015:762956.

16. Goodwin CR, Recinos PF, Omeis I, et al. Prevention of facial pressure ulcers using the Mayfield clamp for sacral tumor resection. J Neurosurg Spine 2011;14(1):85-7.
17. European Pressure Ulcer Advisory Panel (EPUAP), National Pressure Injury Advisory Panel (NPIAP), Pan Pacific Pressure Injury Alliance (PPPIA). Prevention and treatment of pressure ulcers/injuries: clinical practice guidelines. The international guideline. 3rd ed. Emily Haesler, editor. EPUAP, NPIAP, PPPIA; 2019.

18. Australian Commission on Safety and Quality in Health Care. Hospital-acquired complication: Pressure injury; 2016. Available from: https://www.safetyandquality.gov.au/wp-content/ uploads/2018/03/Pressure-injury-detailed-fact-sheet.pdf.

19. Alderden J, Rondinelli J, Pepper G, Cummins M \& Whitney J. Risk factors for pressure injuries among critical care patients: A systematic review. Int J Nurs Stud 2017; 71:97-114.

20. Tayyib N, Coyer F, Lewis P. Saudi Arabian adult intensive care unit pressure ulcer incidence and risk factors: a prospective cohort study. Int Wound J 2016;13(5):912-9.

21. Cox J, Roche S, Murphy V. Pressure injury risk factors in critical care patients: a descriptive analysis. Adv Skin Wound Care 2018;31(7):328-34.

22. Barakat-Johnson M, Coyer F, Lai M, Wand T, White K. The incidence and prevalence of medical device related pressure injuries in intensive care: a systematic review. J Wound Care 2019;28(8):512-521.

23. Sauvage $P$, Touflet $M$, Pradere $C$, et al. Pressure ulcers prevention efficacy of an alternating pressure air mattress in elderly patients: E(2)MAO, a randomised study. J Wound Care 2017;26(6): 30412.

24. Wounds International. International review: pressure ulcer prevention: pressure, friction and microclimate in context. A consensus document. London: Wounds International 2010.

25. Oliveira VM, Piekala DM, Deponti GN, et al. Safe prone checklist: construction and implementation of a tool for performing the prone maneuver. [Checklist da prona segura: construção e implementação de uma ferramenta para realização da manobra de prona]. Rev Bras Ter Intensiva 2017;29(2):131-141.

26. Park SY, Kim HJ, Yoo KH, Park YB, Kim SW, Lee SJ, et al. The efficacy and safety of prone positioning in adults patients with acute respiratory distress syndrome: a meta-analysis of randomized controlled trials. J Thorac Dis 2015;7(3):356-67.

27. Gefen A, Farid KJ, Shaywitz I. A review of deep tissue injury development, detection, and prevention: shear savvy. Ostomy Wound Manage 2013;59(2):26-35.

28. Shi C, Dumville JC, Cullum N. Support surfaces for pressure ulcer prevention: a network meta-analysis. PloS One 2018;13(2):e0192707-e.

29. Rolls K, Jones S, Power D, Cook S, Flood K, Hennessy C, Mackenzie K, Robertson Y, Rodgers J, Blanchfield D, Kuzmiuk L, Fullbrook P. Pressure injury prevention for critically ill adults: a clinical practice guideline. Agency for Clinical Innovation NSW Government Version 1. Chatswood NSW, 2014; ISBN 978-174187-955-1

30. NSQHS Standard 8 Pressure Injury. Definitions sheet 2 V3.0 [Internet]. 2014 Sept 17 [cited 2018 Oct 29]. Available from: https:// www.health.qld.gov.au/_data/assets/pdf_file/0029/433478/pipaudit-def.pdf

31. Yarad E, O'Connor A, Meyer J, Tinker M, Knowles S, Li $\mathrm{Y}$, Hammond $\mathrm{N}$. Prevalence of pressure injuries and the management of support surfaces (mattresses) in adult intensive care patients: a multicentre point prevalence study in Australia and New Zealand. Australian Critical Care 2020. doi:10.1016/j. aucc.2020.04.153. 
32. Fletcher J, Gefen A, Jones L, Sanada H, Irvine M. Hybrid support surfaces made easy. Wounds International 2015.

33. Serraes B, van Leen M, Schols J, Van Hecke A, Verhaeghe $\mathrm{S}$, Beeckman D. Prevention of pressure ulcers with a static air support surface: a systematic review. Int Wound J 2018;15(3):333-43.

34. Capasso V, Cox J, Cuddigan J, Delmore B, Tescher A, Solmos S. Pressure injury prevention-pip tips for prone positioning. National Pressure Injury Advisory Panel 2020.

35. Kwee MM, Ho YH, Rozen WM. The prone position during surgery and its complications: a systematic review and evidence-based guidelines. Int Surg 2015;100(2):292-303.

36. Grisell M, Place H. Face tissue pressure in prone positioning: a comparison of three face pillows while in the prone position for spinal surgery. Spine 2008;15;33(26):2938-41.

37. Roth S. Perioperative visual loss: what do we know, what can we do? Br J Anaesth 2009;103(1):31-40.

38. Katzengold R, Gefen A. What makes a good head positioner for preventing occipital pressure ulcers. Int Wound J 2018;15(2):2439.

39. Levy A, Kopplin K, Gefen A. Device-related pressure ulcers from a biomechanical perspective. J Tissue Viability 2017;26(1):5768.

40. Barakat-Johnson M, Lai M, Gefen A, Coyer F. Evaluation of a fluidised positioner to reduce occipital pressure injuries in intensive care patients: a pilot study. Int Wound J 2017;16(2):424432.

41. McMichael JC, Place HM. Face tissue pressures in prone positioning: a comparison of three pillows. J Spinal Disord Tech 2008;21(7):508-13.

42. Santamaria N, Gerdtz M, Kapp S, Wilson L, Gefen A. A randomised controlled trial of the clinical effectiveness of multilayer silicone foam dressings for the prevention of pressure injuries in high-risk aged care residents: The Border III Trial. Int Wound J 2018;15(3):482-90.

43. Santamaria N, Gerdtz M, Liu W, et al. Clinical effectiveness of a silicone foam dressing for the prevention of heel pressure ulcers in critically ill patients: Border II Trial. J Wound Care 2015;24(8):340-5.

44. Santamaria N, Gerdtz M, Sage S, et al. A randomised controlled trial of the effectiveness of soft silicone multi-layered foam dressings in the prevention of sacral and heel pressure ulcers in trauma and critically ill patients: The Border trial. Int Wound $\mathrm{J}$ 2015;12(3):302-8.

45. Levy A, Frank MB, Gefen A. The biomechanical efficacy of dressings in preventing heel ulcers. J Tissue Viability 2015;24(1):1-11.

46. World Union of Wound Healing Societies (WUWHS) Consensus Document. Role of dressings in pressure ulcer prevention. Wounds International; 2016.

47. Castelino I, Mercer D, Forrest Calland J. Poster presentation at the Symposium on Advanced Wound Care (Spring), Atlanta, Georgia, United States of America, 2012.

48. Yoshimura M, Ohura N, Tanaka J, Ichimura S, Kasuya Y, Hotta O, Kagaya Y, Sekiyama T, Tannba M, Suzuki N. Soft silicone foam dressing is more effective than polyurethane film dressing for preventing intraoperatively acquired pressure ulcers in spinal surgery patients: the Border Operating room Spinal Surgery (BOSS) trial in Japan. Int Wound J 2018;15:188-197.

49. Mölnlycke Health Care. Finite Element Simulation of Pressure Ulcer Prevention at the iliac crest in Operating Room with Mepilex Border Flex, Mölnlycke Health Care, Data on File; 2019.
50. Call E, Pedersen J, Bill B, Oberg C, Ferguson-Pell M. Microclimate impact of prophylactic dressings using in vitro body analog method. Wounds 2013;25(4):94-103.

51. Padula WV. Effectiveness and value of prophylactic 5-layer foam sacral dressings to prevent hospital-acquired pressure injuries in acute care hospitals: an observational cohort study. J Wound, Ostomy Continence Nurs 2017;44(5):413-9.

52. Forni C, D'Alessandro F, Gallerani P, Genco R, Bolzon A, Bombino C, Mini S, Rocchegiani L, Notarnicola T, Vitulli A, Amodeo A Celli G, Taddia P. Effectiveness of using a new polyurethane foam multi-layer dressing in the sacral area to prevent the onset of pressure ulcer in the elderly with hip fractures: a pragmatic randomised controlled trial. Int Wound J 2018 Jun;15(3):383390.

53. Sammon M. Reducing hospital-acquired pressure injuries and the cost of prevention in the OR and ICU setting. Poster presented at Symposium of Advanced Wound Care, 2017. 